\title{
Application of AFM in understanding biomineral formation in diatoms
}

\author{
Mark Hildebrand • Mitchel J. Doktycz • David P. Allison
}

Received: 16 October 2007 / Accepted: 2 November 2007 / Published online: 6 December 2007

(C) Springer-Verlag 2007

\begin{abstract}
We review previous work and present new data on the application of atomic force microscopy (AFM) to study biomineral formation in diatoms, unicellular algae that make cell walls of silica. Previous studies examined a small subset of mostly larger diatom species, identifying a prevalence of large particulate silica on the nanoscale. We survey different structures including valves, girdle bands, and elongated spines called setae, in a variety of species, and show a diversity of nano- and meso-scale silica morphologies, even on different portions of the same structure. A general trend of highly organized mesoscale silica structure on the proximal face of cell wall components was observed, with less organized structure occurring on the distal face. The highly organized structures have features suggestive of an underlying linear template, which defines the area of initial silica polymerization. Such features have not been imaged with such clarity previously, demonstrating the advantages of AFM to image small differences in surface morphology and providing new insights and confirming
\end{abstract}

Invited contribution Special Issue "Nanophysiology", David P. Allison.

M. Hildebrand

Scripps Institution of Oceanography,

University of California-San Diego,

La Jolla, CA 92093-0202, USA

M. J. Doktycz • D. P. Allison

Biological and Nanoscale Systems Group, Biosciences Division, Oak Ridge National Laboratory,

Oak Ridge, TN 37831-6123, USA

D. P. Allison $(\bowtie)$

Department of Biochemistry and Cellular and Molecular Biology, University of Tennessee,

Knoxville, TN 37996-0840, USA

e-mail: allisond@utk.edu evidence for models of diatom silica structure formation. In addition to its imaging capability, more developed application of AFM to map locations of organic template components on the nanoscale will greatly aid in elucidating mechanisms of diatom biosilica synthesis.

Keywords Atomic force microscopy D Diatoms . Mesoscale $\cdot$ Nanofabrication $\cdot$ Nanoscale $\cdot$ Silica . Biomineralization

\section{Abbreviations \\ AFM atomic force microscopy \\ SDV silica deposition vesicle}

\section{Introduction}

Microscopy has played an important role in research relative to cell biology and physiology, beginning with Robert Hook using a primitive optical microscope to describe the cellular structure of cork in 1665 [22], followed 20 years later by Antonie van Leeuwenohoek identifying bacteria with a single lens optical microscope [13, 14]. As optical microscopes became more sophisticated, it became apparent that all life forms were composed of cells. This led Matthias Schleiden and Theodor Schwann, in 1839, to propose the cell doctrine where the cell was the smallest unit of life, living things were composed of one or more cells, and cells arose from existing cells [40, 45, 51]. Development of cellular stains allowed optical microscopy to identify structure within cells including nuclei, golgi, and chromosomes. With the invention of the electron microscope, resolution of lens-based microscopes were extended to the nanoscale where mitochondria, ribosomes, smooth 
and rough endoplasmic reticulum, and both cellular and nuclear membranes were identified.

Although both optical and electron microscopes have made significant contributions to biological research, they are essentially static instruments made so by the requirement for chemical staining to achieve contrast and also, in the case of electron microscopes, the requirement for operating in a vacuum. In 1982, a new type of high-resolution microscope, the scanning tunneling microscope (STM) was invented [2], followed in 1986 by the atomic force microscope (AFM) [3]. Both of these microscopes were well received by biologists because both were capable of atomic resolution and could be used in liquid environment compatible with living systems. The STM imaged by monitoring the position of a biased conductive tip as it is scanned over a conductive sample. By using the voltage required to raise or lower the tip to maintain a constant tunneling current in response to changes in topography, as the $Z$ (height) input, a computer-generated image of the surface could be attained. Because biological samples are basically nonconductive, images with this instrument were infrequent and difficult to repeat. Conversely, the AFM generated a three-dimensional image by monitoring the position of a sharpened tip, supported on a microcantilever mounted on a piezo electric transducer, as it scanned a surface. The AFM could image both conductive and nonconductive surfaces, thereby becoming the instrument of choice for biological investigation. A computer-generated image was accomplished by recording a user-determined number of voltage points for each line scan in the $X$ direction and recording an equal number of line scans in the $Y$ direction resulting in a two dimensional map having $X Y$ voltage coordinates for each point on the map. To create the topographic image, a $Z$ voltage (height) for each of the $X Y$ voltage points was necessary. This is accomplished by reflecting a laser beam off the back surface of the cantilever onto a position sensitive detector (PSD). During scanning, changes in surface topography affect the position of the laser spot on the PSD and therefore the voltage output. By keeping the laser spot in a fixed position on the PSD and by applying a feedback voltage to the scanning mechanism, the tip can be maintained in contact or near contact to the surface. This feedback voltage serves as the $Z$ voltage input for each of the $X Y$ points resulting in a topographic image.

Research that could greatly benefit from application of AFM is the study of biomineral formation, because of the ability to determine three-dimensional surface topology of the hard material without the need of coatings, to determine micromechanical properties, and the possibility of mapping mineral or organic domains at nanometer resolution.

Diatoms are unicellular microalgae that make a composite cell wall of silica and organic material (protein and carbohydrate) and are recognized as useful model systems for understanding biomineralization. They generally range in size from a few microns up to several hundred microns, with typical average sizes of $15-30 \mu \mathrm{m}$. Most striking is the variety of silica structures diatoms make on the nano- to micrometer scale (Fig. 1). Diatom species are classified according to their silica structures, and the total number of species is estimated in the tens- to hundreds-of-thousands; thus, an enormous variety of structures exist.

The diatom silica cell wall as a whole is called the frustule, and it is divided into two overlapping halves called thecae: the upper being the epitheca and lower being the hypotheca (Fig. 2). The general structure of a diatom frustule is similar to a Petri dish (Fig. 2), consisting of valves, which are the distinctive species-specific structures capping the top and bottom, and girdle bands, which are a series of overlapping siliceous strips that surround the cell to form the sides, and also provide overlap between the two thecae (Fig. 2). There are two general morphological types of diatoms based on their valve structures: the centrics, which have rotational symmetry, and the pennates, which have bilateral symmetry [39]. Diatom silica is made from the soluble precursor form of silicic acid, which is transported into the cell $[19,20]$ and into a specialized membranebound compartment called the silica deposition vesicle $[8$, $11,36,44]$, or SDV, where it is polymerized to form the mineral. Once the mineral structure of the valve or girdle band is completed, it is moved in its entirety across the plasma membrane (exocytosed), where it becomes an exoskeleton surrounding the cell.

There are three scales of silica structure formation in diatoms, the micro-, meso-, and nanoscale [9, 21]. Determinants involved in the formation of micro- and nano-scale structures are at least partially characterized, but we understand little about what generates the mesoscale. The microscale is the overall outline structure of the valves and girdle bands, which is determined by shaping of the SDV through active and passive molding [39]. A major aspect of this shaping involves components of the cytoskeleton-actin and microtubules, which apparently dynamically define and expand the SDV [4, 6, 43, 49]. Much more remains to be determined about the interaction of the cytoskeleton and SDV, how the overall SDV shape is defined by the cytoskeleton, and how SDV membrane components interact with the cytoskeleton. Structures on the nanoscale are formed as a result of the initial polymerization of silica and manifest as the silica "texture" seen in high resolution images. Characterization of organic components tightly associated with diatom silica suggests that major determinants of nanoscale structure are long chain polyamines (LCPAs), which catalyze silica polymerization [25], and silaffins, which are (poly)peptides proposed to play a regulatory role in silica polymerization by 

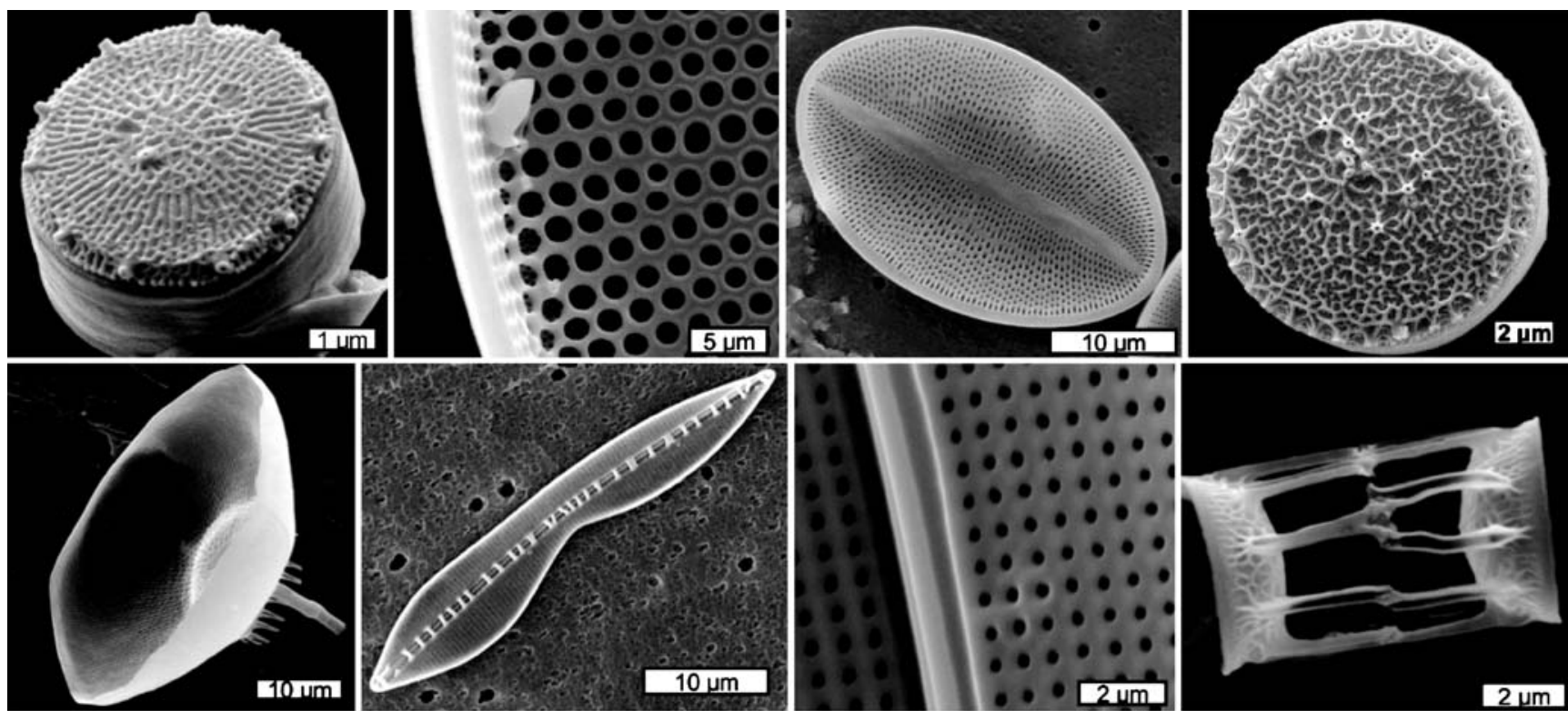
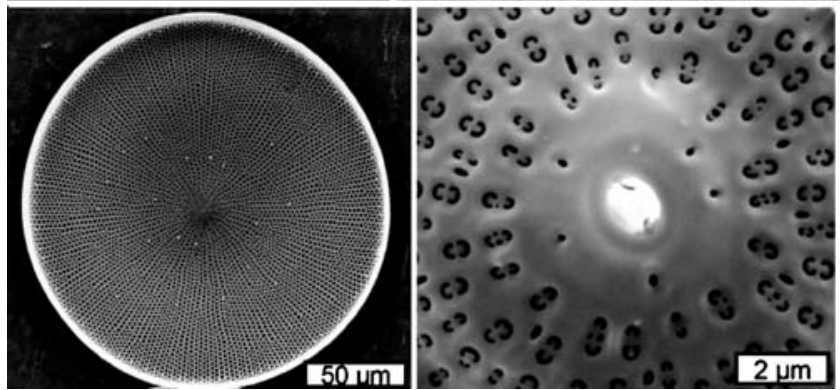

Fig. 1 Diversity of diatom silica structures. Samples of acid-clean silica from a variety of diatom species imaged by SEM. Scale bars are labeled. Upper panel, left to right, Thalassiosira pseudonana, detail of Coscinodiscus wailesii, Cocconeis sp., and Thalassiosira weissflogii.

organizing LCPAs via electrostatic interactions [26, 27, 35]. In vitro, LCPAs and silaffins isolated from diatoms precipitate silica to form a variety of morphologies [25-27, 35], but these lack the higher order structure seen in a diatom frustule. In diatoms, higher order is seen on the mesoscale, in which substructures consisting of organized patterns of nanoscale polymerization products are formed within the confines of the microscale of the SDV. Little is known about mesoscale organizational components, but as most of the species-specific differences in diatom silica structure occur at the mesoscale, further investigations will be important to understand how these components contribute to generating species-specific differences.

\section{Investigating mesoscale formation of diatom silica structures}

Investigations using SEM and transmission electron microscopy (TEM) examining structural intermediates have led to observationally based concepts and models of how diatoms form their silica structures $[9,33,37]$. From these
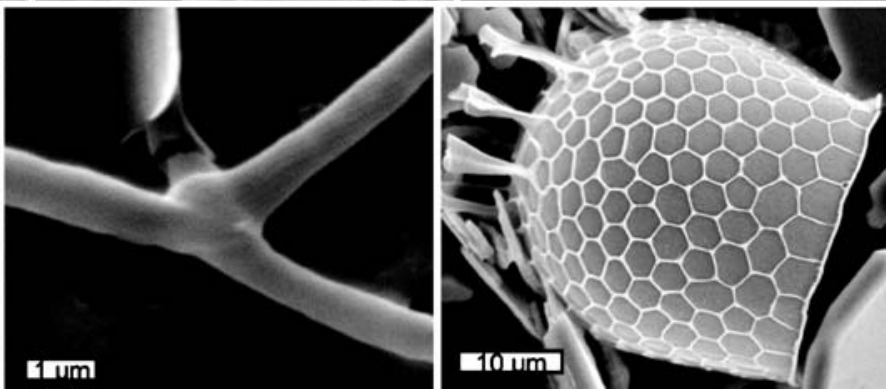

Middle panel, left to right, Ditylum brightwellii, Bacillaria paxillifer, Gyrosigma balticum, and Skeletonema costatum. Lower panel, left to right, Coscinodiscus wailesii, detail of Ditylum brightwellii, detail of setae in Chaetoceros laciniosis and Stephanopyxis turris

studies, it is clear that shaping and molding of the SDV (which involves the cytoskeleton) dictate overall microscale morphology. Mesoscale structure has been proposed to occur either by templating of an organic material (protein or carbohydrate) internal to the SDV [9, 33, 37], by a diffusion-based chemical process [17], by self-association of silaffins and LCPAs [24, 35, 46], or by phase separation involving LCPAs [47]. Close examination of detailed structure formation in diatoms that make complicated threedimensional structures [41, 42] indicate a level of control over all aspects that is not consistent with solely diffusionbased, self-association, or phase separation process. This is not to discount the contribution of chemical or diffusional processes; for example, the lumen of the SDV has been measured at a low $\mathrm{pH}$ [50], which would be conducive to silica polymerization [23], and based on in vitro work, chemical influences such as self-association of silaffins and LCPAs, which appear to be essential for polymerization $[27,46]$, are likely to occur in vivo as well. The discovery that LCPAs are amphiphilic and can self-associate led to the suggestion that sequential formation of LCPA droplets, and their subsequent incorporation into silica could, by phase 


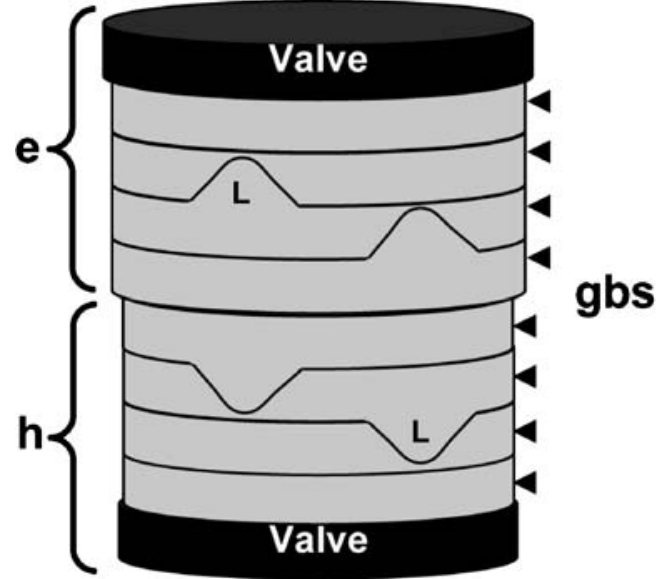

Fig. 2 Schematic diagram of diatom cell wall structure. The overall structure of the cell wall, called a frustule, is similar to a Petri dish, with an upper half called the epitheca $(e)$ that overlaps the lower half called the hypotheca $(h)$. The extreme upper and lower portions capping the thecae are called valves, which are the silica structures diagnostic of a particular species. The sides of the thecae are comprised of a series of overlapping girdle bands ( $g b$, arrows), which are silicified bands encircling the cell. There is a bell-shaped curve in one part of the girdle band called the ligula ( $L$ denoting two of four depicted). In T. pseudonana, girdle bands are not complete rings, but have a break opposite the ligula, which taper to precisely fit the ligula in the adjacent girdle band. Also in T. pseudonana, the girdle band break is not exactly opposite the ligula; instead it is offset by a regular distance, resulting in staggering of ligulae along the thecae

separation, generate a series of smaller and smaller circular silica structures as were seen in the valve of Coscinodiscus species [47]. This is an intriguing possibility, but examination of actual structural intermediates in formation of the Coscinodiscus valve [42] indicates that other factors are involved; for example, linear silica structures are initially deposited to form the base layer of the valve, which is not consistent with a circular droplet template, and the three dimensional aspect of structure formation is not accounted for in the model. An important observation, clearly apparent in the formation of three dimensional silica structures in Coscinodiscus wailesii and Thalassiosira eccentrica, is that distinct structures are formed on different internal (luminal) faces of the SDV [41, 42]. This was most recently observed during examination of structural intermediates in valve formation in T. pseudonana [21]. In this species, the circular valve is formed by ribs of silica radiating outward from the center, with the ribs branching to maintain a regular spacing (Fig. 3a,b). The spaces between the ribs eventually fuse, forming a thin silica base layer with the full outline of the valve but without structural rigidity [21]. Formation of the base layer involves expansion in the $x / y$ axis plane. After base layer formation, the rim of the valve is built up, followed by additional silica being deposited in the valve center, to form a rigid structure [21]. This involves expansion in the $z$-axis direction. We coined the term "spatial cementing" to describe the initial light deposition of silica to delineate the outline of the final structure in the $x / y$ plane, followed by additional deposition and $z$-axis expansion to form a more rigid structure [21]. In the examples of $C$. wailesii, T. eccentrica, and T. pseudonana, $z$-axis expansion and deposition occurs only in one direction, towards the distal (outer) valve face [21, 41, 42]. Unidirectional $z$-axis expansion has been documented in other diatom species as well [7], indicating that the SDV has "sidedness." A model has been developed suggesting an interaction between anchoring components (possibly from the cytoskeleton) on the outside of the proximal face of the SDV that organizes polymerization components in the SDV lumen on the same face, through the intermediaries of membrane-spanning proteins [9, 37]. This model is entirely consistent with observations of the initial deposition of valve base layers to form the outline of mesoscale structure. Other factors such as chemical effects, phase separation, or ordered assembly of organics may play a larger role in $z$-axis expansion.

SEM and TEM have been the predominant techniques used to examine diatom silica structure formation and will continue to be highly useful in this regard. However, AFM is intrinsically better at measuring surface topography than EM and so should complement these other techniques. AFM is especially able to reveal slight differences in surface height, which may be indicative of underlying organic templates. It also can provide information on micromechanical properties. Surprisingly, few studies have applied AFM to diatoms, and most of those have focused on examination of soft diatom extracellular materials, providing measurements of elasticity and strength. For this reason, only a portion of this review can discuss previous work; therefore, we include a substantial amount of original data to illustrate specific points.

\section{Previous AFM examinations of diatom silica}

The first AFM examinations of diatom silica were by Almqvist et al. [1] on the pennate diatom, Navicula pelliculosa, and Crawford, et al. [8] on the pennates, Pinnularia viridis and Hantzschia amphioxys. These are all freshwater diatom species; $N$. pelliculosa is small (valve is $3 \times 7 \mu \mathrm{m}$ ), whereas $P$. viridis and $H$. amphioxys are large (valves are about $100 \times$ 25 and $75 \times 16 \mu \mathrm{m}$, respectively). The study on $N$. pelliculosa was focused mainly on micromechanical measurements (hardness and elasticity), but some high resolution images were obtained, revealing a smooth, non-particulate, silica morphology [1]. The nanostructure was described as shallow hillocks, $10-20 \mathrm{~nm}$ in diameter and 1-2 $\mathrm{nm}$ high [1]. Such detail could not be imaged by scanning electron microscope (SEM) [5]. Hardness and elasticity were measured by nanoindentation and deflection, and overall properties were 
similar to other silicas, but high resolution mapping revealed significant differences in hardness and elasticity in different portions of the valve. An initially deposited region of the valve called the central nodule $[1,5]$ consisted of the thickest silica and had the greatest hardness and elasticity, on the order of $30-100 \mathrm{~s}$ of GPa measured by both indentation and deflection [1]. Different locations in a central rib region were 15-30 or 40-100 GPa measured by indentation or deflection, respectively, and the outermost transapical rib region had values of 7-15 or 8-20 GPa [1]. These data indicated that hardness and elasticity generally decreased towards the edges of the valve. This study demonstrated that such measurements could be made on diatom silica and correlated micromechanical properties with previously determined stages in formation of the structure in this species.

Examination of $P$. viridis focused on imaging and mechanical property measurements of extracellular mucilage covering the silica and the silica itself [8]. Scanning of the AFM tip across the surface enabled removal of the mucilage, revealing silica surface features. The surface was quite smooth, although high resolution revealed some small-scale granularity, and other larger-scale features were superimposed on the basic structure [8]. Force curves of the surface showed that the material was noncompressible. Cleaned frustules cleaved by sonication revealed that the silica in cross-sections was particulate and granular, in contrast to the smooth material at the valve surface. Images from height data indicated that the silica was loosely packed, suggesting the material was porous. The average diameter of silica particles was consistent in several areas of the valve and in the girdle bands at 45 and $40 \mathrm{~nm}$, respectively [8]. In cross-sections of $H$. amphioxys, similar particulate silica was seen, with average diameter of 37 or $38 \mathrm{~nm}$ in the valves and girdle bands, respectively. The statistically significant difference in silica particle size between species, but not between girdle bands and valves in the same species, suggested species-specificity in nanoscale silica formation. Silaffins and LCPAs from different diatom species can form silica precipitates of different size classes and morphologies [25, 27, 35], which could explain the underlying mechanism for nanoscale size differences identified in P. viridis and H. amphioxys [8].

Silica on the valve surface of the large centric diatom Coscinodiscus granii was examined by AFM [3] and, in contrast to $P$. viridis and $H$. amphioxys, did not have a smooth texture, but instead was granular, consisting of amalgamated particles of silica, $100-200 \mathrm{~nm}$ in diameter. In another study on Coscinodiscus sp., a similar arrangement of silica was observed, with particle sizes between 50 $80 \mathrm{~nm}$ in diameter [29]. A rigorous nanoindentation study
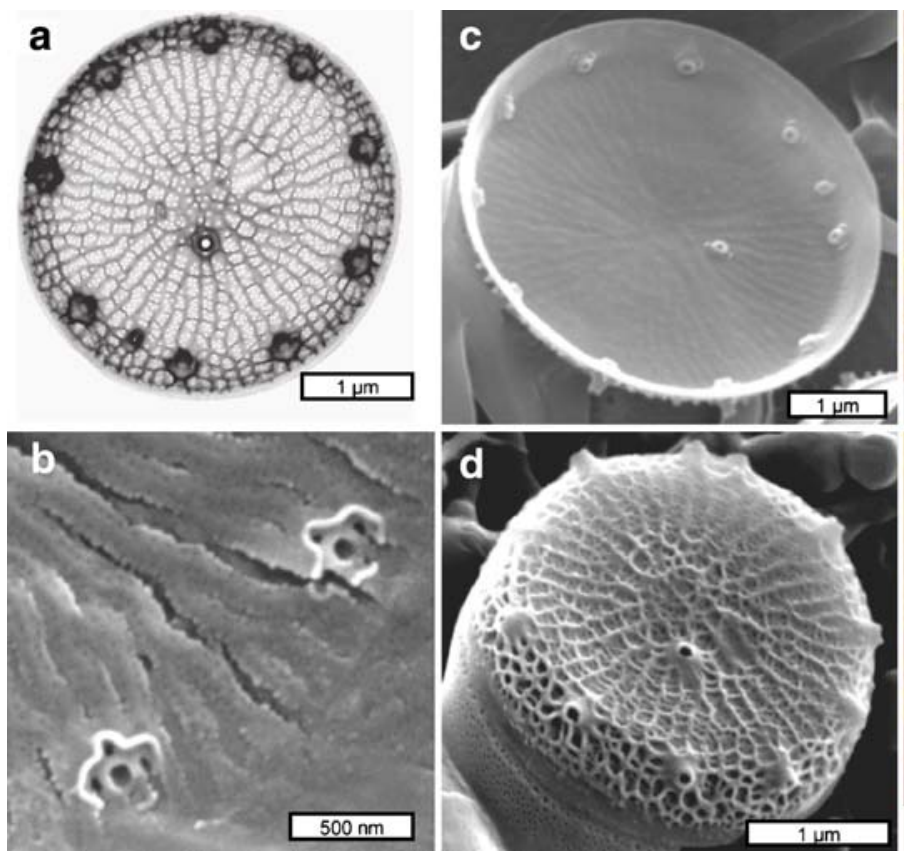

Fig. 3 AFM reveals different silica morphologies on different valve faces of Thalassiosira species. a-f, Thalassiosira pseudonana, $\mathbf{g}-\mathbf{h}, T$. weissflogii. a TEM of T. pseudonana valve showing the branched rib structure. b SEM of developing valve ribs, showing their flattened nature. c SEM of inner (proximal) valve surface, which is very smooth. d SEM of outer (distal) valve surface, showing ridged structure. e AFM of the proximal valve surface, confirming its
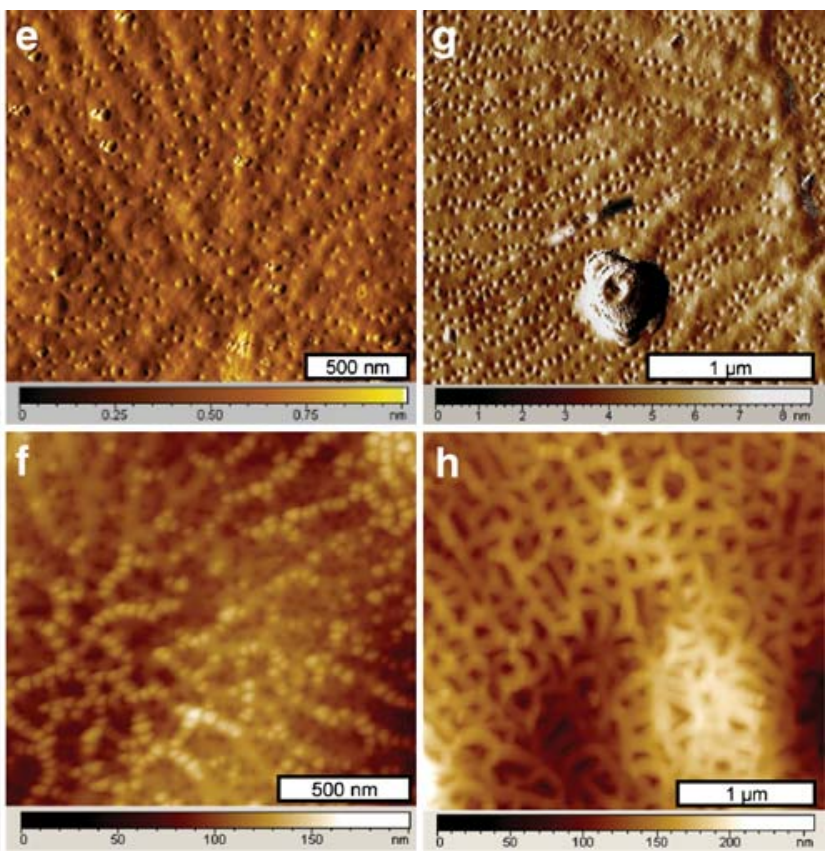

smoothness. f AFM of the distal valve surface, on which $50 \mathrm{~nm}$ spherical silica particles topping the ridges can be seen. $\mathrm{g}$ AFM of proximal valve surface of $T$. weissflogii, showing similarity to $T$. pseudonana. h AFM of distal valve surface of T. weissflogii, showing intricate tubular structure. Images $\mathbf{a}-\mathbf{f}$ are from [21], used with permission 
on this species monitored hardness and elasticity in four distinct structural features [30]. Hardness varied from 0.059-0.53 GPa and elastic modulus from 1.7-6.51 GPa, depending on the feature and its location [30].

With the exception of $N$. pelliculosa, all diatom silica structures examined by AFM were from exceptionally large species. The possibility of bias in nanoscale structural features because of overall cell size is a distinct possibility, which led us to initiate a survey of different and more typically-sized, species. All samples were prepared by acid treatment to remove organics [21]. Diatom silica samples, suspended in distilled water, were prepared for AFM imaging by placing a $10-\mu 1$ aliquot of the sample on gelatincoated mica, spreading the sample with a micropipette tip and allowing the sample to air dry [10]. After drying, samples were imaged in contact mode in a PicoPlus AFM (Molecular Imaging, Tempe AZ) under environmental control ( $12 \%$ relative humidity) using silicon nitride cantilevers with manufacturer's suggested spring constant of $0.1 \mathrm{~N} / \mathrm{m}$.

\section{Examination of valves in different Thalassiosira species provides insight into conserved and distinct silica formation processes}

As mentioned, the initial stage of valve formation in $T$. pseudonana involves deposition of branching ribs of silica that eventually fuse to form a base layer. This is followed by $z$-axis growth of silica on top of the ribs to form ridges [21]. SEM images indicated that the proximal (inner) valve surface was relatively smooth, whereas the distal surface was ridged (Fig. 3c,d). AFM imaging confirmed the smoothness of the proximal surface, but ribs were more apparent, although the height difference between them and adjacent valleys was $<10 \mathrm{~nm}$ (Fig. 3e). The high-resolution surface imaging capability of AFM revealed that the distal ridged surface, which in most SEM images appeared to be solid, actually consisted of about $50 \mathrm{~nm}$ diameter individual spherical silica particles that were partly fused along the ridge axes (Fig. 3f). Other images of the distal valve surface (data not shown) indicated areas where the particles were absent, and only the ribs of the base layer were visible, indicating that particle formation was not uniform and providing clues as to their mechanism of formation [9]. AFM examination of a related Thalassiosira species, $T$. weissflogii, also indicates a highly conserved smooth proximal valve surface (Fig. 3g), with ribs being about $47 \%$ wider than T. pseudonana but with center-to-center rib spacing and patterning nearly identical. If rib formation is mediated by an organic template, this new data suggests either possible differences in the width of the template in the two species or the ability of the template and its immediate environment (chemical properties or polymerizing determinants) to spatially influence silica polymerization. The conserved rib spacing and patterning of ribs indicates similar mesoscale control over formation of these structures in both species. Examination of the distal valve surface in $T$. weissflogii reveals dramatically different silica morphology compared with $T$. pseudonana, consisting of a latticework of interconnected silica tubes (Fig. 3h). The tubes bear some relation to the underlying base layer but have a much greater tendency towards forming crossconnections compared with $T$. pseudonana. These data indicate a divergent mechanism involved in structure formation during $z$-axis expansion in T. pseudonana and T. weissflogii.

\section{Formation of valves in centric diatoms involves radial deposition of linear structures}

During valve formation in centric diatoms, initial deposition of linear ribs arranged radially from the center is commonly observed [33, 39]. Even in pennate species, initial deposition of linear structures is prevalent $[5,33,39]$. Radial ribs are visible in a forming valve of Ditylum brightwellii imaged by AFM (Fig. 4a), but the ability to image detailed surface topography at high resolution (Fig. 4b) revealed in this species that the rib silica appeared
Fig. 4 Deposition of radial branched silica ribs in valve formation. a AFM of a forming valve of Ditylum brightwellii. b Close-up of a, arrows locate particulate silica nanoscale structures on one of the mesoscale ribs. c AFM of branched rib structure in valve of Chaetoceros laciniosis, showing the lack of particulate nanoscale structure
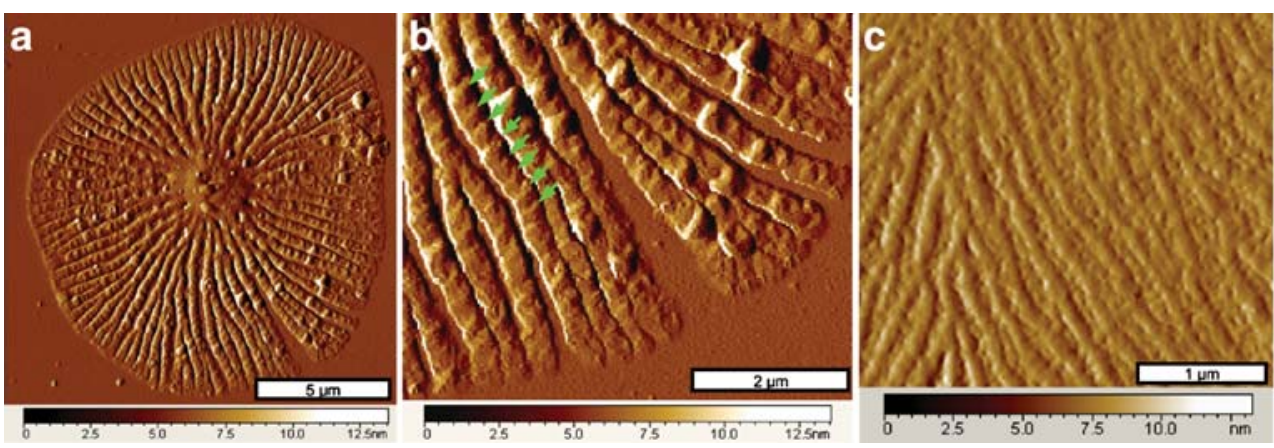
to consist of fused particles (Fig. $4 \mathrm{~b}$, arrows), in contrast to the smooth rib nanostructure in the Thalassiosira species (Fig. 3) or C. laciniosis (Fig. 4c). This suggests that the underlying nanoscale polymerization determinants in the different species have different properties but share the ability to organize or be organized to form similar mesoscale rib structures.

\section{AFM enables visualization of girdle bands at the micro-, meso-, and nanoscale}

Girdle bands are essential to the integrity of the diatom cell but have been little studied due to their generally less ornate structure compared with valves and difficulty in imaging due to their small size and thinness, which makes them relatively transparent to electrons. Although it is clear that girdle bands are synthesized in an SDV [28, 33], mechanisms of formation are not known, nor what constitutes the difference between a girdle band SDV and valve SDV. A first step in understanding the mechanism of formation of girdle bands is to be able to image the object at high resolution-fortunately, AFM allows this.

Girdle bands generally have a microscale hoop-like structure that encircles the cell. They are most commonly split rings, with a discontinuity on one side, but there are examples of complete rings or scale-like girdle bands that cover a smaller area [39]. Girdle bands have a bell-shaped section called the ligula, and for split rings, a taper at the ends farthest away from the ligula, where on the adjacent girdle band, its ligula precisely fits (Fig. 2). When assembled in the cell, the ends of the girdle band can be positioned directly opposite the ligula in the same girdle band, but in T. pseudonana, the two ends are slightly different in length; hence, the ligula are staggered with each successive girdle band [21]. Girdle bands also overlap each other, starting with the one that is overlapped by the valve then successively overlapping those further from the valve.

AFM imaging of scale-like girdle bands from $D$. brightwellii (Fig. 5) shows micro-, meso-, and nanoscale features. On the microscale, the ligula is clearly defined by a filamentous outline (Fig. 5a), which must be a property of material defining the circumference of the SDV. In one class of imaged girdle bands (Fig. 5a), on the mesoscale, the girdle band has a regular striated structure, with pores between the striations. Pores adjacent to a given striation are similarly, but not necessarily exactly, positioned. In another class of girdle bands (Fig. 5b), a highly textured morphology consisting of irregularly shaped and sized silica particles was observed. Examination of girdle bands that were folded over (data not shown) indicates that the two morphologies represented different faces of the girdle band. Based on previous SEM examination of girdle bands

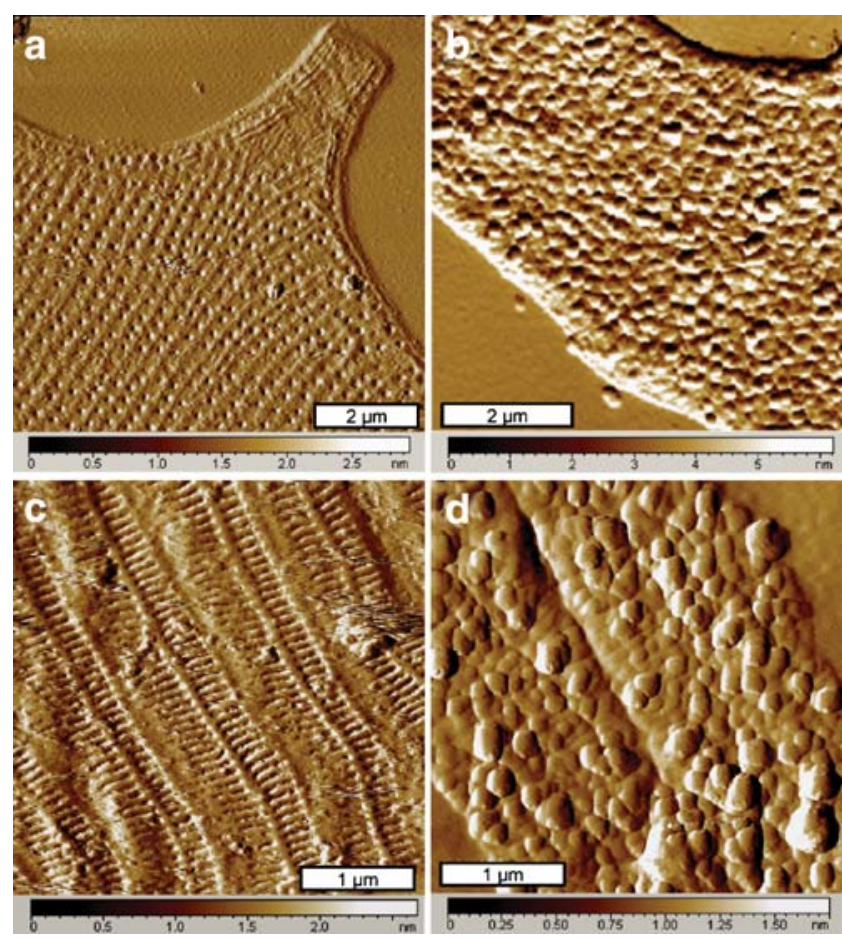

Fig. 5 AFM imaging of girdle bands enables resolution of micro-, meso-, and nanoscale structure. a Proximal surface of $D$. brightwellii girdle band, indicating microscale molding around the ligula, bordered by a filamentous silica border and mesoscale striations in the body of the girdle band. b Distal surface of D. brightwellii girdle band, demonstrating particulate nanoscale silica morphology. c Series of overlapping girdle bands, proximal surface, from Skeletonema costatum, showing striated structure. d Distal surface of $S$. costatum girdle band, indicating particulate nanoscale silica morphology

in T. pseudonana with similar features [21], we assume that the striated girdle band in Fig. 5a is a view of the proximal surface, and the textured girdle band in Fig. $5 \mathrm{~b}$ is the distal surface. The particles on the distal face do exhibit alignment along the axis of the striations on the proximal face (Fig. 5b). This data suggests a situation similar to the valve in T. pseudonana, where an organized base layer is first formed, followed by a less organized distal layer that provides rigidity.

Examination of a series of overlapping girdle bands in Skeletonema costatum also shows striated structure until the region of overlap, where the material seems to flatten and become more smooth (Fig. 5c). A region of smooth silica was observed in the region of overlap between adjacent girdle bands in T. pseudonana [21], and a similar feature seen in other diatom silica structures suggests that inhibition of expansion of the SDV may play a role in their formation $[9,18]$. In $S$. costatum, a filament runs perpendicular to the striations along the long axis of the girdle band (Fig. 5c). On the distal face of the girdle band, the silica morphology is irregular and particulate, and appears even less ordered than in D. brightwellii (Fig. 5d). 


\section{AFM examination of setae reveals insights into structure formation mechanisms}

Certain diatom species make hollow tubular extensions called setae. Setae are a diagnostic feature of species in the genus Chaetoceros [12, 16, 38] and can be quite long relative to the dimensions of the cell; for example, the frustule of $C$. gracilis is approximately $4 \times 6 \mu \mathrm{m}$, but at each corner is a seta extending 25-45 $\mu \mathrm{m}$ [38]. Depending on the species, in cross-section, setae can be circular, square, triangular, or polygonal [12]. Commonly, along the length of setae are small spines that project outward slightly; the spines can have a regular pattern of arrangement. Setae of C. gracilis are circular tubes of approximately $300 \mathrm{~nm}$ diameter, with spines arranged in a right handed twist (approximately every $32^{\circ}$ ) moving towards the tip (Fig. 6a). At the tips, the setae flatten and reveal individual components (Fig. 6a), consisting of a series of longitudinal ribs with a right-handed twist of $5.5^{\circ}$ that terminate in spines, which are also apparent in the tubular portion (Fig. 6a). Closer examination shows a highly regular repeat structure to the longitudinal ribs (Fig. 6b). Such a regular

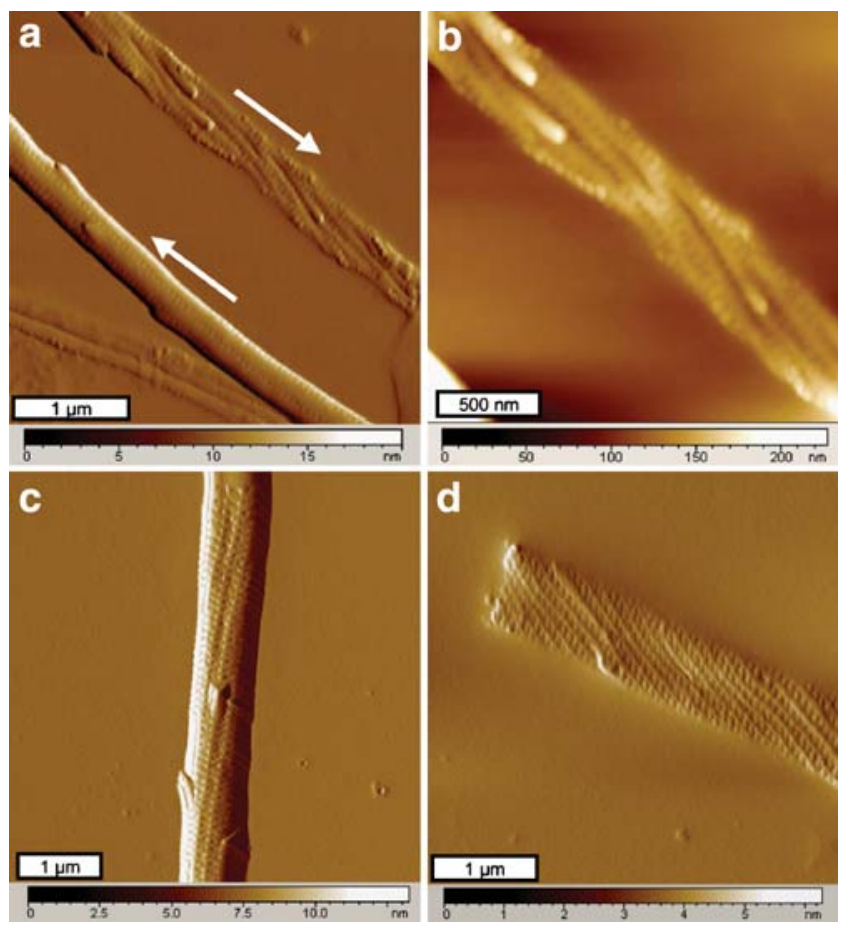

Fig. 6 AFM imaging of setae in Chaetoceros gracilis, C. diversum, and C. laciniosis. a C. gracilis setae, lower left is a fully formed seta, upper right is a seta in formation. Arrows denote direction of tip. b Higher resolution image of forming seta, highlighting the longitudinal ribs with spines at the tips and the regular repeating substructures comprising the ribs. c $C$. diversum seta, showing similar helical twist, but distinct nanoscale repeating structure compared with $C$. gracilis. d Tip of $C$. laciniosis seta, indicating tighter helical twist and distinct nanoscale features compared with the other two species repeat suggests the possibility of an underlying regularly repeating template.

Examination of setae in $C$. diversum and $C$. laciniosis show species-specific differences (Fig. 6c,d). The helical twist of setae in $C$. diversum is only slightly greater than in C. gracilis, but there is more complexity to the repeating subunit structure, and the spines have a different shape (Fig. 6c). In C. laciniosis, the helical twist is much tighter $\left(33.5^{\circ}\right)$, and the surface structure is yet distinct from the other two species (Fig. 6d).

These observations indicate that setae are formed from longitudinal ribs of silica that are assembled together with a species-specific helical twist. The first stage of the process is the formation of the longitudinal ribs, followed by rigid connection between the ribs to form an overall tubular structure. The ribs are composed of regularly repeating subunits that enable stepwise linear extension and provide the cross-connections between adjacent ribs. Previous investigations into setae formation in two Chaetoceros species using TEM identified intracellular details of the process [32, 34]. In C. peruvianis, "finger-like" outgrowths of silica were first formed, followed by lateral connections [34]. This is similar to what is observed by AFM-initial deposition of longitudinal ribs followed by formation of lateral connections (Fig. 6b). However, TEM revealed that the connections were initially fully formed of a regularly repeating complex of organic material [34]. Assuming a similar process occurs in $C$. gracilis, unsilicified organic material could have been destroyed near the setae tips during the acid cleaning used in our preparations, resulting in the separated longitudinal ribs seen (Fig. 6b).

\section{Novel insights into diatom biosilicification revealed by AFM}

Even the few examples presented in this paper demonstrate that the ability to image surface topography at high resolution by AFM provides highly useful insights into understanding diatom silica structure formation. AFM enabled imaging of distinct silica morphologies on the proximal and distal valve faces of Thalassiosira (Fig. 3), without interference from artificial coatings. Ribs in the base layer of the Thalassiosira species were clearly seen by AFM, whereas even with high resolution SEM, ribs are not clearly delineated because height information is lacking. Conservation of base layer features in the two Thalassiosira species suggests common processes involved in their formation. Height information from AFM in general is useful in imaging nanoscale features resulting from silica polymerization in diatoms, as evidenced by the spherical silica 
particles on ridges of the outer T. pseudonana valve surface (Fig. 3f), the textured surface of $D$. brightwellii valve ribs (Fig. 4b), and different silica morphologies in the proximal and distal faces of girdle bands (Fig. 5).

One clear conclusion from this study is that there is not a single basic building block unit of silica comprising the diatom frustule, and that distinct and multiple morphologies are common in the same species. Thirty to fifty $\mathrm{nm}$ spherical silica particles are present in a variety of diatoms [8, 31; Figs. 3 and 5]; however, other morphologies with little or no detectable nanoscale texture are present in the same species (Figs. 3 and 5). Because of their prevalence in structures resulting from $z$-axis expansion, indications are that the large silica particles may be useful for filling in large spaces but may not play a significant templating role because they are observed in stages subsequent to a linear templating process.

Girdle bands are difficult to image in detail by SEM or TEM because of their thinness. AFM proves ideal for imaging these structures, and a wealth of details on micro-, meso-, and nanoscale features are apparent (Fig. 5). AFM imaging reveals similar construction features in the girdle bands as in the valves - linear features perhaps relating to an underlying template on the proximal surfaces and less ordered silica particles on the distal surfaces (Fig. 5). This suggests that template association with one face of the SDV may be a general feature of formation of different structures in diatoms. Continuing application of AFM to study girdle bands is likely to be fruitful in understanding the mechanisms of formation and similarities and differences between girdle band and valve formation.

AFM imaging of setae also enabled visualization of substructures not previously documented in such detail. Particularly important in this regard was imaging the regularly repeating structure in C. gracilis setae (Fig. 6b). Previous TEM work revealed intracellular aspects of setae formation, but could not provide details of the forming silica morphology $[32,34]$. Our images indicate an initial structure consisting of individual longitudinal ribs made of repeating subunits of defined structure (Fig. 6b). Also evident are species-specific differences in helical twist and detailed surface morphology, which had been visualized by SEM [12] but without such clarity. There are advantages of AFM compared with SEM or TEM in elucidating some details of the surface topography of the setae.

AFM not only provides information on silica structures but gives insight into features of possible underlying organic templates that may be involved in structure formation. Low-relief surface features are not easy to image by SEM because height information is minimal, and can only be seen by TEM when the object is in cross-section, but AFM is ideal for this. One general theme revealed in this study is the prevalence of linear mesoscale templates, even in diverse complex-curved valves, girdle bands, and setae microscale structures. This suggests the likelihood of a class of linearly assembling SDV-associated proteins involved in organizing silica polymerization determinants.

\section{Advantages and limitations of SEM, TEM, and AFM to image diatom biominerals}

Characterization of diatoms at high resolution has relied upon SEM or TEM imaging. SEM has the advantage of high resolution (depending on the instrument), the ability to image large changes in height and large areas. Its limitations are that coatings are sometimes required, which could mask or distort some nanoscale features, and its inability to obtain small scale height information. TEM has high resolution, but the electron transparency of many materials (including biosilica) can make it difficult to distinguish between different layers, and surface imaging is only possible with a thin section containing a surface slice or in cross-section. AFM has the highest resolution of the three techniques and can provide nanoscale height information and the most detailed surface topography, without the need for coatings. Its limitations are that it can be difficult to image large changes in height due to the limits posed by the movement of the $Z$ piezo scanning element that in most AFM's is limited to about $10 \mu \mathrm{m}$. Another limitation for imaging the larger diatoms is the $X Y$ scan range that is limited to about $100 \mu \mathrm{m}$. The radius of curvature of the AFM cantilever tip also causes a broadening of structure in the lateral dimensions, and care must be taken when interpreting structure in this plane [48].

\section{Future directions}

As evidenced by the few examples previously published $[1,8,31]$ and shown in this paper, there is continued use for AFM in the study of diatom biomineralization. With the exception of the image of forming ribs in D. brightwellii in Fig. 4, thus far, only the completed silica structures have been imaged. Examining intermediates is a highly useful approach to understand the process of structure formation $[5,21]$ and would likely benefit from application of AFM to monitor nano- and mesoscale features. Micromechanical properties of diatom silica have been measured [1, 8, 30], but measuring such properties in structural intermediates should provide insight into mechanisms of synthesis.

A key area in which AFM could be applied is in high resolution mapping of organics and possible inorganic 
domains in diatom biosilica. AFM tips can be functionalized with a variety of organic molecules, including peptides, proteins, or antibodies, and specific interactions between the tip molecules and sample can be probed [15]. For example, specific proteins could be precisely located relative to specific silica structures by applying antibodies against that protein. Once localized, one could evaluate the forces of interaction between that protein and other components. The ability to measure precise changes in physical properties, directly interrogate specific molecules, and image at a variety of scales down to nanometer resolution indicates the power and versatility of AFM for the study of diatom silicification.

Acknowledgements A portion of this research was conducted at the Center for NanophaseMaterials Sciences, which is sponsored at Oak Ridge National Laboratory by the Division of Scientific User Facilities, US Department of Energy. The Oak Ridge National Laboratory is managed by UT-Battelle, LLC, for the USDOE under Contract No. DE-AC05-00OR22725. This work was also supported by Air Force Office of Scientific Research Multidisciplinary University Research Initiative Grant RF00965521.

\section{References}

1. Almqvist N, Delamo Y, Smith BL, Thomson NH, Bartholdson A, Lal R, Brzezinski M, Hansma PK (2001) Micromechanical and structural properties of a pennate diatom investigated by atomic force microscopy. J Microsc 202:518-532

2. Binnig G, Röhrer H (1982) Scanning tunneling microscopy. Helv Phys Acta 55:726-735

3. Binnig G, Quate CF, Gerber C (1986) Atomic force microscope. Phys Rev Lett 56:930-933

4. Blank GS, Sullivan CW (1983) Diatom mineralization of silicic acid VI. The effects of microtubule inhibitors on silicic acid metabolism in Navicula saprophila. J Phycol 19:39-44

5. Chiappino ML, Volcani BE (1977) Studies on the biochemistry and fine structure of silica shell formation in diatoms VII. Sequential cell wall development in the pennate Navicula pelliculosa. Protoplasma 93:205-221

6. Cohn SA, Nash J, Pickett-Heaps JD (1989) The effect of drugs on diatom valve morphogenesis. Protoplasma 149:130-143

7. Cox EJ (1999) Variations in patterns of valve morphogenesis between representatives of six biraphid diatom genera. J Phycol 35:1297-1312

8. Crawford SA, Higgins MJ, Mulvaney P, Wetherbee R (2001) Nanostructure of the diatom frustule as revealed by atomic force and scanning electron microscopy. J Phycol 37:543-554

9. Davis A, Hildebrand M (2007) Molecular processes of biosilicification in diatoms. Metal Ions Life Sci (in press)

10. Doktycz MJ, Sullivan CJ, Hoyt PR, Pelletier DA, Wu S, Allison DP (2003) AFM imaging of bacteria in liquid media immobilized on gelatin coated mica surfaces. Ultramicroscopy 97(1-4):209-216

11. Drum RW, Pankratz HS (1964) Post mitotic fine structure of Gomphonema parvulum. J Ultrastruc Res 10:217-223

12. Evensen DL, Hasle GR (1975) The morphology of some Chaetoceros species as seen in the electron microscopes. Nova Hedw Beihefte 53:153-184

13. Ford BJ (1995) First steps in experimental microscopy, Leeuwenhoek as practical scientist. Microscope 43(2):47-57
14. Ford BJ (1981) The van Leeuwenhoek specimens. Notes Rec R Soc 36(1):37-59

15. Fotiadis D, Scheuring S, Muller SA, Engel A, Muller DJ (2002) Imaging and manipulation of biological structures with AFM. Micron 33:385-397

16. Fryxell GA (1978) Chain-forming diatoms: Three species of Chaetoceros. J Phycol 14:62-71

17. Gordon R, Drum RW (1994) The chemical basis of diatom morphogenesis. Int Rev Cytol 150:243-372

18. Hildebrand M, Wetherbee R (2003) Components and control of silicification in diatoms. In: Muller WEG (ed) Progress in molecular and subcellular biology, silicon biomineralization. Springer, Heidelberg, pp 11-57

19. Hildebrand M, Dahlin K, Volcani BE (1998) Characterization of a silicon transporter gene family in Cylindrotheca fusiformis: Sequences, expression analysis, and identification of homologs in other diatoms. Mol Gen Genet 260:480-486

20. Hildebrand M, Volcani BE, Gassmann W, Schroeder JI (1997) A gene family of silicon transporters. Nature 385:688-689

21. Hildebrand M, York E, Kelz JI, Davis AK, Frigeri LG, Allison DP, Doktycz MJ (2006) Nano-scale control of silica morphology and three-dimensional structure during diatom cell wall formation. J Mater Res 21:2689-2698

22. Hooke R (1665) Micrographia: or, Some physiological descriptions of minute bodies made by magnifying glasses, $1 \mathrm{st}$ edn. Martyn and Allestry, London

23. Iler RK (1979) The chemistry of silica: solubility, polymerization, colloid and surface properties, and biochemistry. Wiley-Interscience, New York

24. Kröger N, Sumper M (2004) The molecular basis of diatom biosilica formation. In: Baeuerlein E (ed) Biomineralization: progress in biology, molecular biology, and application. WileyVCH, Weinheim, pp 137-158

25. Kröger N, Deutzmann R, Bergsdorf C, Sumper M (2000) Speciesspecific polyamines from diatoms control silica morphology. Proc Natl Acad Sci U S A 97:14133-14138

26. Kröger N, Deutzmann R, Sumper M (1999) Polycationic peptides from diatom biosilica that direct silica nanosphere formation. Science 286:1129-1132

27. Kröger N, Lorenz S, Brunner E, Sumper M (2002) Self-assembly of highly phosphorylated silaffins and their function in biosilica morphogenesis. Science 298:584-586

28. Kröger N, Wetherbee R (2000) Pleuralins are involved in theca differentiation in the diatom Cylindrotheca fusiformis. Protist 151:263-273

29. Losic D, Rosengarten G, Mitchell JG, Voelcker NH (2006) Pore architecture of diatom frustules: Potential nanostructured membranes for molecular and particle separations. J Nanosci Nanotech 6:982-989

30. Losic D, Short K, Mitchell JG, Lal R, Voelcker NH (2007) AFM nanoindentations of diatom biosilica surfaces. Langmuir 23:5014 5021

31. Noll F, Sumper M, Hampp N (2002) Nanostructure of diatom silica surfaces and of biomimetic analogues. NanoLett 2:91-95

32. Pickett-Heaps J (1998) Cell division and morphogenesis of the centric diatom Chaetoceros decipiens (Bacillariophyceae) II. Electron microscopy and a new paradigm for tip growth. J Phycol 34:995-1004

33. Pickett-Heaps J, Schmid A-MM, Edgar LA (1990) The cell biology of diatom valve formation. In: Round FE, Chapman DJ (eds) Progress in phycological research. Biopress, Bristol, pp 1168

34. Pickett-Heaps JD, Carpenter J, Koutoulis A (1994) Valve and Seta (spine) morphogenesis in the centric diatom Chaetoceros-peruvianus Brightwell. Protoplasma 181:269-282 
35. Poulsen N, Kröger N (2004) Silica morphogenesis by alternative processing of silaffins in the diatom Thalassiosira pseudonana. $\mathrm{J}$ Biol Chem 279:42993-42999

36. Reimann BEF, Lewin JC, Volcani BE (1966) Studies on the biochemistry and fine structure of silica shell formation in diatoms. II. The structure of the cell wall of Navicula pelliculosa (Breb.) Hilse. J Phycol 2:74-84

37. Robinson DH, Sullivan CW (1987) How do diatoms make silicon biominerals. TIBS 12:151-154

38. Rogerson A, De Freitas ASW, McInnes AG (1986) Growth rates and ultrastructure of siliceous setae of Chaetoceros gracilis (Bacillariophycea). J Phycol 22:56-62

39. Round FE, Crawford RM, Mann DG (1990) The diatoms: Biology and morphology of the genera. Cambridge University Press, Bath

40. Schleiden MJ (1838) Beiträge zur Phytogenesis. Arch Anat Physiol Wiss Med 13:137-176

41. Schmid A-M, Schulz D (1979) Wall morphogenesis in diatoms: deposition of silica by cytoplasmic vesicles. Protoplasma 100: 267-288

42. Schmid A-MM, Volcani BE (1983) Wall morphogenesis in Coscinodiscus wailesii. I. Valve morphology and development of its architecture. J Phycol 19:387-402
43. Schmid A-MM (1980) Valve morphogenesis in diatoms: a patternrelated filamentous system in pennates and the effect of APM, colchicine, and osmotic pressure. Nova Hedwiga 33:811-847

44. Schmid AM, Borowitzka MA, Volcani BE (1981) Morphogenesis and biochemistry of diatom cell walls. In: Kiermayer O (ed) Cytomorphogenesis in plants. Springer, New York, pp 63-97

45. Schwann T (1839) Mikroskopische Untersuchungen über die Übereinstimmung in der Struktur und dem Wachstum der Tiere und Pflanzen. Sander'schen Buchhandlung, Berlin

46. Sumper M, Kröger N (2004) Silica formation in diatoms: the function of long-chain polyamines and silaffins. J Mater Chem 14:2059-2065

47. Sumper M (2002) A phase separation model for the nanopatterning of diatom biosilica. Science 295:2430-2433

48. Thundat T, Zheng X-Y, Sharp SL, Allison DP, Warmack RJ, Joy DC, Ferrell TL (1992) Calibration of atomic force microscope tips using biomolecules. Scan Microsc 6(4):903-910

49. van de Meene AML, Pickett-Heaps JD (2002) Valve morphogenesis in the centric diatom Proboscia alata Sundstrom. J Phycol 38:351-363

50. Vrieling EG, Gieskes WWC, Beelen TPM (1999) Silicon deposition in diatoms: control by the $\mathrm{pH}$ inside the silicon deposition vesicle. J Phycol 35:548-559

51. Wilson Edmound B (1896) The cell in development and inheritance, 1st edn. Mcmillan, New York 